Journal of Environmental Science and Public Health

doi: $10.26502 /$ jesph.96120043

Volume 3, Issue 1

Review Article

\title{
Introduction of Petroleum Hydrocarbons Contaminants and its Human Effects
}

\author{
Sylvia Adipah* \\ Department of Environmental Engineering and Science, Chongqing University, Chongqing, China \\ *Corresponding Author: Sylvia Adipah, Department of Environmental Engineering and Science, Chongqing \\ University, Chongqing, China, E-mail: $\underline{\text { fransil351@yahoo.com }}$
}

Received: 27 November 2018; Accepted: 14 December 2018; Published: 07 January 2019

\begin{abstract}
The aim of this study is to introduce soil contamination as a serious worldwide problem. Soil contamination is caused mainly by the leakage of underground storage tanks and pipes. The most common conventional method for the remediation of contaminated soils is excavation followed by landfilling or incineration and other technologies that have been widely practiced. Contaminated sites pose a threat to human life due to severe health problems caused by adverse health effects from exposure to oil-soil contamination. Once it is being detected, assessment strategies, type of sampling, chemical analyses, evaluation of parameters and its effect must be done. Several technologies and parameters have been developed to treat petroleum hydrocarbon contaminated soil but the problem still exists.
\end{abstract}

Keywords: Soil contamination; Remediation; Hazardous effect; Hydrocarbons; Contaminant

\section{Introduction}

The soil is a fundamental and irreplaceable natural resource, which provides an essential, link between the components (air, bedrock, water, and biota) that make up our environment, this components interact with each other to provide essential needs like food, fuel, and fiber to support the organism [1]. Soil contaminated by petroleum hydrocarbons is a serious worldwide environmental problem that has been attracting public attention over the past decades. Human activities are one of the major factors that contribute to the spill of hydrocarbons through 
agriculture or industrial products. Although petroleum is one of the dominant energy sources to maintain the economic and social development of a country, petroleum has become one of the most important types of organic pollutant and is caused by the main leakage of underground storage tanks and accidental spills during transportation and disposal. Total petroleum hydrocarbons in the presence of soil have a negative impact on human health and the development of plant growth. With the expanding of the soil contaminated by petroleum hydrocarbons effort have been made to remediate total petroleum hydrocarbons contamination in soil. Spills, leaks and other environmental factors associated with petroleum products cause hazards to human health. Chemicals involved are petroleum hydrocarbons, polycyclic aromatic hydrocarbons (PAHs), solvents, pesticides, lead, and other heavy metals [2]. Contaminants can enter the soil from the point source (industrial and households) and diffuse source (mobilization and transportation by floodwaters) that can have long-term implications for the quality and functioning of soils as well as human health and food quality [1].

In developing and developed countries, the main sources and polluting activities may vary from each other. In

Europe, contaminated oil is caused by industrial and commercial activities as a result of the treatment or disposal of waste [3]. There are various methods of remediating oil-contaminated soil such as bioremediation, soil vapor extraction, soil washing, thermal treatment, and chemical oxidation but the most common conventional method is excavation followed by landfilling or incineration [4]. However, excavation and landfilling is costly and does not only destroy contaminants but also cause secondary pollution such as the formation of volatile organic compounds (VOCs). In Europe, 3.5 million sites are estimated to be potentially contaminated [5]. Studies have proved that there is a lack of sufficient qualitative and quantitative data due to rehabilitating and restoring soil contamination and also it results in great costs to the society [6]. Due to this, U.S. Environmental Protection Agency (USEPA) has proposed; physical, chemical, biological and thermal approaches for treating soils contaminated by petroleum hydrocarbons.

\section{Health Effects of Oil Contaminated Soil}

Natural gas, crude oil, tars, and asphalt are types of petroleum hydrocarbons [7]. The word petroleum means "rock oil" or "oil from the earth" [2]. Petroleum used in our daily life plays a vital role in our modern society. It is the main energy source for heating, transportation, and manufacturing, but acts as a raw material for plastic and synthetic rubber. Total Petroleum Hydrocarbons (TPHs) are used to describe mixtures of organic compounds found in or derived from crude oil that has the potential to be most toxic [8]. It's made up of hydrogen and carbon but may also contain sulfur, nitrogen, heavy metals, and oxygen compounds. Most products that contain total petroleum hydrocarbons (TPHs) can burn easily. Some are clear or light colored liquids that evaporate easily, and others are thick, dark liquids or semi-solids that do not evaporate [9] and many of these products (gasoline, kerosene etc.) have oily odors. Modern society uses so many petroleum-based products (for example gasoline, kerosene, fuel oil, mineral oil, and asphalt), widespread environmental contaminants [9]. 
The composition of petroleum hydrocarbons (PHCs); varies slightly by its source, but the toxic properties are consistent. Chemicals such as benzene and polycyclic aromatic hydrocarbons (PAHs) are extremely toxic components of high concern [10]. According to the U.S. Environmental Protection Agency [11], determining the risk of petroleum releases requires a synthesis of both hazard and exposure information. The risk of exposure through skin contact or ingestion is related to the tendency of a particular compound to absorb onto soil particles and also into vegetation through root uptake, which may enter the food chain [12]. In addition, the risk of exposure through inhalation is related to the tendency of a compound to volatilize either directly from the soil or from water sources that have become impacted subsequent to its release [12]. Also, the solubility and the specific gravity of a compound influence the way and degree to which a chemical can impact surface or groundwater supplies, thereby influencing the risk of exposure through these pathways [9]. Contaminated soil affects human health through inhalation mixture of chemicals being vaporized from contaminated soil [13]. Pollutants type or pathway of attack can have an adverse health effect on the exposure of a population [14].

If exposures are high, death can occur [9]. Breathing toluene at concentrations greater than 100 parts per million (100 ppm) for more than several hours can cause fatigue, headache, nausea, and drowsiness. According to Centers for disease control and Prevention (CDC) when exposure is stopped, symptoms will go away but if exposure takes a longer time permanent damage to the central nervous system can occur, also benzene at sufficient concentrations is known to be associated with higher incidence of leukemia [15]. Many chlorinated solvents induce liver changes, kidney changes and depression of the central nervous system [9]. Other health effects such as a headache, nausea, fatigue, eye irritation, and skin rash are of high concern. According to the Environmental Protection Agency, Washington D.C (USEPA), exposure through direct contact, inhalation, or ingestion of soil contaminants can cause death.

\subsection{Impact of total petroleum hydrocarbons (TPHs) on environment}

When TPH is released into the environment through accidents, releases from industries, or as a by-product from commercial or private uses and/or into the soil through spills or leaks, it moves from the soil to the groundwater and some organisms found may break down some of the contaminants [9] into smaller fractions while some may evaporate into the atmosphere, others will stay in the soil for a longer time and will be broken down by other organisms found in the soil causing hazardous health effect [16]. According to Environmental Protection Agency (USEPA) [11], TPH releases into the environment will threaten public health and safety by contaminating drinking water, causing fire and explosion hazards, diminishing air and water quality, compromising agriculture, destroying recreational areas, destroying habitats and food, and wasting non-renewable resources. Once the soil is polluted by petroleum hydrocarbons (PHCs) the recovery may take several years. Yang et al. reported that the Qingdao oil pipeline explosion that has resulted to contamination of the soil was due to human error thus poor planning and maintenance of the pipeline, and negligence after it was found to be leaking. As mentioned below Petroleum hydrocarbons contaminated soil is a concern for a number of reasons (Figure 1). First of all, once released into the soil, the volatility of PHCs can pose a fire or even explosion hazards, especially when vapor enter confined spaces. 
Contaminants can interfere with nutrient and water transmission leading to land degradation. Petroleum residuals may stay bound to soil particles and remain in the soil for years. Although contaminants may benefit from carbon source as degrader they are still toxic to the majority of soil biota. PHCs may destroy the aesthetic by inducing offensive odor, taste or appearance in environmental media. Lastly, PHCs will pose a potential threat to the environment.

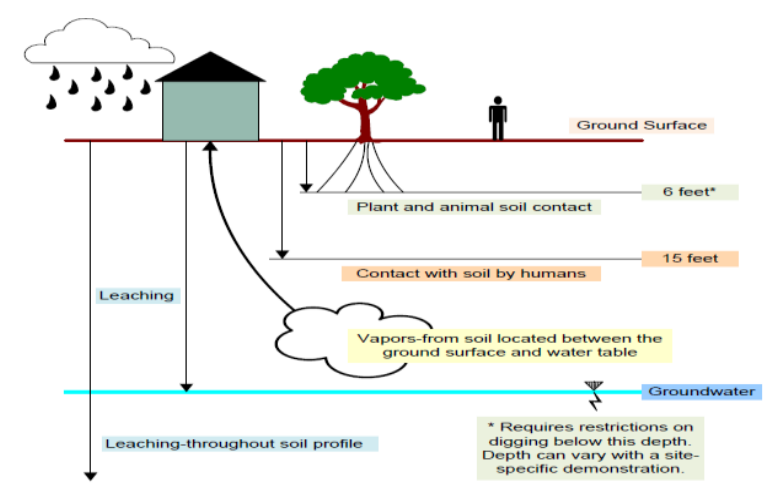

Figure 1: Soil points of compliance for various exposure pathways. Source: Robin, 2000.

\subsection{Fate of petroleum hydrocarbons (PHCs) in the soil}

Soil is one of the natural resources, which need to be protected with utmost attention and care although only a meter in depth over the earth's surface, soil is a key to sustaining life affecting air and water quality, the growth of plants and crops, and the health of the entire planet [17]. The soil is able to degrade more chemicals quickly and bring its components back to their natural cycles, in which it minimizes the environmental disturbance brought by contamination [17]. The interactions between petroleum hydrocarbons and soil, however, are extremely complex. Petroleum hydrocarbons are made up of complex of mixtures of hundreds of compounds [18] ranging from light, volatile, short chained organic compounds to heavy, long chained, branched compounds. The major hydrocarbon fractions have different environmental fates [9] and the degradability of simple hydrocarbons and petroleum fuels decreases as molecular weight and degree of branching increases [19]. The exact composition of petroleum products varies depending upon the source of crude oil and refining practices used to produce the product.

Once the oil is spilled into the environment, thousands of compounds are formed, mainly hydrocarbons and a small proportion of nitrogen, sulfur, and oxygen, in their right proportion are produced [20]. The fate of PHCs following an oil spill is summarized below in Figure 2, Once the PHCs is released into the soil, depending on their chemical properties the complex PHCs mixture then separate into individual compounds. Compounds with lower molecular weight e.g. BTEX compounds (Benzene, Toluene, Ethylbenzene, and the Xylenes) are naturally occurring constituents of gasoline and diesel although also present in kerosene and fuel oils. BTEX compounds are highly mobile in environments and more volatile and easily leach to the groundwater than PHCs of higher molecular weight $[9,10]$. Thus compared to motor oil, gasoline having lighter compounds can break down and volatilize more easily. The amount of oil spilled also has an impact on the leaching of PHCs to the groundwater. Site-specific 
factors e.g. terrain, climate, vegetation and soil inherent properties can also affect the rate of bulk oil filtration [20, 9]. Generally, hydrocarbons with straight chain and few chains can degrade more readily than those with complex chains [9]. Compounds with longer chains, such as PAHs and aromatics tend to bind strongly to soil particles and soil organic matter plays a vital role in the degradation of contaminants $[9,10]$. Many exposure pathways need to be evaluated for petroleum hydrocarbon contaminated soils across media in nature (leaching of chemicals in soils to groundwater) and thus require analysis of chemical fate to be evaluated. However, more trials and methods are needed since the nature of contaminants varies in different sites and countries.

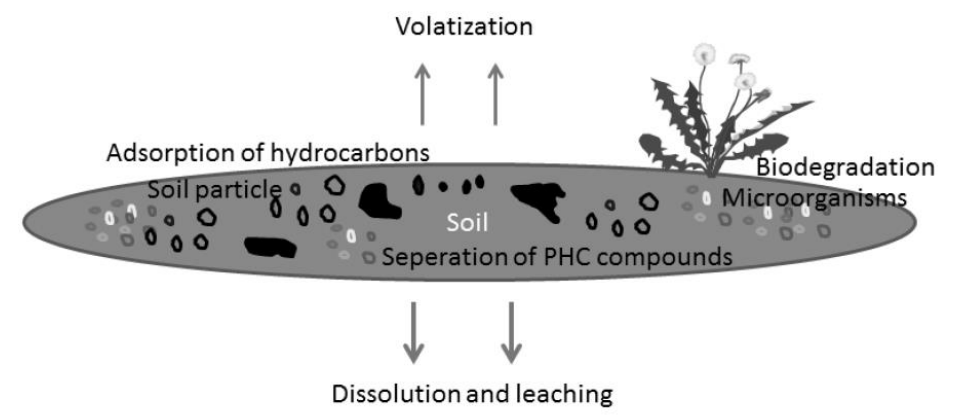

Figure 2: Physical and biochemical behavior of petroleum hydrocarbons in the soil. Source: [9].

\section{The Previous Study on Remediation of TPH Contaminated Soil using Different Oxidation} Chemical Methods

European Commission [21] states that "Remediation shall consist of removal, control or reduction of contaminants that will no longer pose any significant risk to human health or the environment". Enormous effort has been made to find efficient and effective ways to remediate petroleum contamination in the soil since increased attention has been paid for developing innovative technology for cleaning up these contaminants. The conventional methods used in remediating petroleum hydrocarbons contaminated soil are broadly divided into physical, chemical and biological methods $[12,22]$ but the most common conventional method for the remediating of contaminated soil was excavation followed by landfilling or incineration, due to limitations and drawbacks of these methods thus causing secondary pollution that might pose along treat to the environment $[19,22]$ technologies such as bioremediation, soil vapor extraction, soil washing, thermal treatment and chemical oxidation has been developed [12,22] for treating contaminated soil.

Contaminants can be treated either by in-situ or ex-situ. In in-situ remediation requires treating the contaminated material in place while ex-situ involves the physical removal of the soil and contaminants from the polluted site to be treated elsewhere $[23,24]$. Here among the conventional methods being mentioned above, Chemical oxidation treatment using Ozone, permanganate, persulfate, and Fenton's oxidation will be of its significance. 


\subsection{Techniques for analyzing TPHs contaminated soil}

In 1999, the USEPA evaluated field methods to determine Total Petroleum Hydrocarbons in soils. This was an ambitious project that involved the establishment of TPHs definition and the development of a reference method for its quantification.

At present, a wide variety of specific and non-specific methods were used for analysis of TPH. The conventional non-specific methods includes i) field screening gas chromatography with flame ionization (GC-FID) or photoionization detection (GC-PID) [25], ii) gravimetric determination and infrared spectrometry (IR), such as USEPA methods 418.1, 8440, and 9071B or American Society for Testing and Materials [26] iii) turbidimetry [26], iv) ultraviolet and fluorescence spectroscopy [27], v) thin layer chromatography (TLC) which have been used extensively in the component of various characteristics of oils and respective fractions [28], vi) high-performance liquid chromatography (HPLC) [29], vii) supercritical fluid chromatography (SFC) [30], viii) isotope ratio mass spectrometry [31], and ix) fiber optic IR sensor for identification of various petroleum samples [32]. Techniques from the previous study have been implemented to assess, identify and quantify petroleum contaminants that exist in the soil [28]. Fingerprints analysis has been developed using specific and advanced techniques such as i) gas chromatography-mass spectrometry (GC-MS), ii) high-performance liquid chromatography-mass spectrometry (HPLC-MS), iii) isotope dilution mass spectrometry (IDMS), iv) nuclear magnetic resonance (NMR), and v) electrospray ionization mass spectrometry (ESI-MS) [33, 34]. Many USEPA and ASTM methods have been modified to improve selectivity and sensitivity for measuring spilled oil and petroleum products in soils [27]. Schwartz [35] reported that using field measurement methods instead of laboratory analysis was possible to analyze more soil samples faster and at the lower cost. Lambert, et al. [36] used two test kits for soil analyses: the immunoassay-based Enviro Gard petroleum fuel in soil test kits and a colorimetric test procedure. Sadler [37] analyzed the performance of the PetroFLAG hydrocarbon analyzer system (commercial version of SW- 846 Method 90747) using co-elution in a single step chromatography separation. In their study, it was impossible to identify and quantify the target compounds. Combined methods such as HPLC- GC, GC-GC, GC $\times$ GC (two dimensional GC), or supercritical fluid chromatography (SFC) is commonly used to improve the quality of the analysis. Lynn et al. [4] used SFC-GC/MS for detailed analysis of different hydrocarbon group's and the range of petroleum fractions. Mao et al. [38] estimated the eco-toxicity of petroleum hydrocarbons mixtures in soil using HPLC-GC $\times$ GC. All these analytical methods have been modified in order to eliminate matrix interferences, reduced the amount of solvent used, find alternative and less toxic solvents, simple analytical procedures amongst other requirements.

\subsection{Assessment of oil contaminated soil}

According to the millennium ecosystem assessment 2005, for the future generation, human actions causing environmental and human hazards must be studied and policies set to sustain the environment (ecosystem) and human health that disrupt the lives of people living in close proximity to oil camps, wells, pumping stations, and pipelines. An environmental Hazard management plan has to take measures to ensure that petroleum hydrocarbon contaminated soil is properly managed in the future and heavily contaminated soils must be treated to ensure that 
human health and the environment remain protected. In order to enhanced petroleum hydrocarbon removal efficiency and rate, more powerful oxidations conditions must be applied and a critical success factor for chemical oxidation is the accurate amount of oxidant. (Frequent supplement of ferrous ion to persulfate oxidation is required in the future field application to maintain a high oxidative power). Adsorption behavior of TPHs should be studied since it helps to reduce the concentrations of organic substances in the soil. A careful treatability study should be performed not only to evaluate the remedial efficiency but also to explore and implement the potential of secondary contaminants. More researchers have to be encouraged to collect data and evaluate remedial alternatives.

\section{Conclusion}

Contaminated sites pose a threat to human life due to severe health problems caused by adverse health effects from exposure to oil-soil contamination once it is being detected, assessment strategies, type of sampling, chemical analyses, evaluation of parameters and its effect must be done. Several technologies have been developed to treat petroleum hydrocarbon contaminated soil but the problem still exists. Contaminated soils must be treated to ensure that human health and the environment remain protected.

\section{References}

1. Department for Environment, Food and Rural Affairs DEFRA. Soil strategy for England supporting evidence paper (2009).

2. US Environmental Protection Agency USEPA. Crude and Petroleum Products (2011).

3. Environmental Agency EEA. Progress in management of contaminated sites (2007).

4. Lynn TB, Lynn AC, Balog D. Analysis of SITE program TPH field trial data for SW-846 method 9074The PetroFLAG Hydrocarbon Analyzer (2002).

5. European Commission EC. Thematic strategy for soil protection (2006).

6. European Commission EC. Questions and answers on the Thematic Strategy on soil protection (2006).

7. Frick CM, Farrell RE, Germida JJ. Assessment of Phytoremediation as an In-Situ Technique for Cleaning Oil-Contaminated Sites (1999).

8. Canadian Council of Ministers of the Environment CCME. Canada-wide standards for petroleum hydrocarbons (PHC) in soil (2001).

9. ATSDR. Toxicological profile for petroleum hydrocarbons (PHC) (1999).

10. Kamath R, Rentz JA, Schnoor JL, et al. Phytoremediation of hydrocarbon-contaminated soils (2007).

11. USEPA. Developing innovative solutions for oil spill cleanup (2007).

12. US Environmental Protection Agency USEPA. The behavior of Effects of Oil Spill in Aquatic Environments (2011).

13. Cheng Y, Nathanail PC. Generic Assessment Criteria for human health risk assessment of potentially contaminated land in China (2009).

14. Brevik EC, Burgess LC. Soils and Human Health. Boca Raton: CRC Press (2013).

15. WHO. Ten chemicals of major health concern (2013). 
16. Nardini E, KisandV, Lettieri T. Microbial Biodiversity and Molecular Approach. Aquatic microbial world and biodiversity: Molecular Approach to improve the knowledge (2010).

17. Bohn HL, Mcneal BL, O’Connor GA. Soil chemistry Second Edition (2001).

18. Epps AV. Phytoremediation of Petroleum Hydrocarbons (2006).

19. Shukla KP. Bioremediation: Developments, Current Practices and Perspectives. Genetic Engineering and Biotechnology Journal (2010).

20. CCME. Backgrounder-Petroleum Hydrocarbons in Soil (2001).

21. European Commission EC. Proposal for a Directive of the European Parliament and of the Council establishing a framework for the soil protection of soil and amending directive (2006).

22. Zhu X, Venosa AD, Suidan MT. Literature review of the use of commercial bioremediation agents for cleanup of oil-contaminated estuarine environments (2004).

23. Kapley A, Purohi HJ. Genomic tools in bioremediation (2009).

24. Boopathy R. Factors limiting bioremediation technologies. Bioresource Technology 74 (2000): 63-67.

25. Saari P Peramaki, Jalonen J. Effect of sample matrix on the determination of total petroleum hydrocarbons (TPH) in soil by gas chromatography-lame ionization detection (2007).

26. USEPA. Non-halogenated organics using GC/FID. USEPA, Washington, DC (2003).

27. ASTM D. Standard Practice for Classification of Soils for Engineering Purposes (2006).

28. Okparanma RN, Mouazen AM. Determination of total petroleum hydrocarbon (TPH) and polycyclic aromatic hydrocarbon (PAH) in soils: A review of spectroscopic and non-spectroscopic techniques (2013).

29. Krahn M, Wigren C, Pearce R, et al. New HPLC cleanup and revised extraction procedures for organic contaminants (2003).

30. Dulaurent A, Dahan L, Thiebaut D, et al. Extended simulated distillation by capillary supercritical fluid chromatography (2007).

31. Abrams MA. Surface geochemical calibration research study: An example of research partnership between academia and industry (2002).

32. Malley DF, Yesmin L, Wray D, et al. Application of near-infrared spectroscopy in analysis of soil mineral nutrients (1999).

33. Pasquini. Near infrared spectroscopy: fundamentals, practical aspects and analytical applications (2003).

34. Forrester ST, Janik LJ, McLaughlin MJ, et al. Total petroleum hydrocarbon concentration prediction in soils using diffuse reflectance infrared spectroscopy. Soil Science Society of America Journal 77 (2013): 450-460.

35. Schwartz G, Ben-Dor, Eshel G. Quantitative analysis of total petroleum hydrocarbons in soils: comparison between reflectance spectroscopy and solvent extraction by 3 certified laboratories (2012).

36. Lambert P, Fingas M, Goldthorp MJ. An evaluation of field total petroleum hydrocarbon systems. J Hazard Mater 83 (2001): 65-81.

37. Sadler R, Connell. Analytical methods for determination of total petroleum hydrocarbons in soil (2003).

38. Mao D, Lookman R, Van De Weghe H, et al. Flemish Institute of technological research (VITO) (2009). 
39. Agency for Toxic Substance and Disease Registry ATSDR. ToxFAQs for total petroleum hydrocarbons (TPH) (1999).

40. ATSDR. Minimal risk levels for priority substances and guidance for derivation, republication (2002).

41. CCME. Canada-Wide Standard for Petroleum Hydrocarbons (PHC) in Soil (2008).

42. European Commission EC. Thematic Strategy for Soil Protection (2002).

43. Lee BT, Kim KW. Ozonation of diesel fuel in unsaturated porous media. Applied Geochemistry 17 (2002): 1165-1170.

44. Robbins GA. Expedited Site Assessment: The CD. Prepared for the Connecticut Department of Environmental Protection (2000).

45. USEPA. How to effectively Recover Free Product at Leaking Underground Storage Tanks Site: A Guide for State Regulators. EPA 510-R-96-001 (2012).

46. USEPA. In-Situ Chemical Oxidation-Engineering Issue (2006).

47. USEPA. Analysis of Selected Enhancement for Soil Vapor Extraction (1997).

48. US Department of Agriculture USDA. Conservation buffers work ecomically and environmentally (2000).

49. Yan H, Sun W. Influence of Fenton oxidation on soil organic matter and its sorption characteristics. Journal of Agro-Environment Science 144 (2006): 164-170.

50. EEA. Human health toxicological assessment of contaminants in soil (2009).

Citation: Sylvia Adipah. Introduction of Petroleum Hydrocarbons Contaminants and its Human Effects. Journal of Environmental Science and Public Health 3 (2019): 001-009.

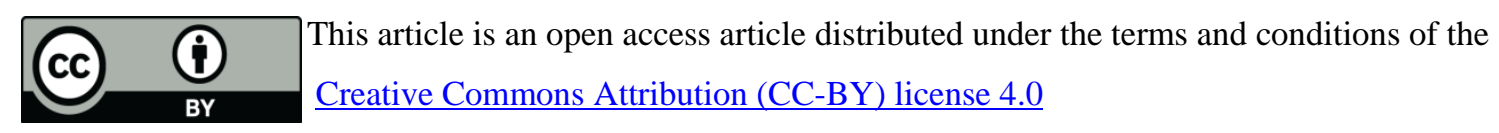

